many editions, and it says little for the method of maximum likelihood if, as soon as it produces an estimator that challenges preconceived ideas, it is over-ruled. Although conditional likelihood arguments can be advanced to justify $n-\mathrm{r}$ as a divisor, the joint estimation of $\mu$ and $\sigma^{2}$ gives the above values, and these values maximise the likelihood. The fact that the estimate of $\sigma^{2}$ is biassed is neither here nor there, and the unacceptable estimate of $\sigma^{2}$ obtained when $n=\mathrm{I}$ is simply an unfortunate consequence of maximum likelihood.

This is a book poised midway between the age of correlation and the age of the computer (neither of which is mentioned). It provides an unhurried and thorough account of the elementary aspects of the linear model, and some excellent introductory material. For teaching these topics, it can be recommended.

A. W. F. EdWARds.

\title{
THE GENETIC RISK FROM RADIATION
}

THE EFFECTS OF ATCMIC RADIATICN. Report of the United Nations Scientific Committee. United Nations, New York. 1966. Pp. (iii) +153. \$2.50.

This report deals with two aspects of radiation: environmental levels and genetic risks. Both topics are presented in the form of short statements outlining present views, followed by long annexes giving the background information in detail and having extensive bibliographies. The non-genetic part of the report contains a re-evaluation of the contributions which radiation from natural sources and from nuclear weapons tests make to the exposure of human populations. There is plenty of information on such subjects as the changing levels of strontium-9o in milk and in human bone.

The evaluation of genetic risks is the third of its kind made by the Committee; previous ones were dated $195^{8}$ and ig62. The present report is, of course, particularly concerned with advances in knowledge since the latter date. However, enough information on previous findings is given to make the genetic annex reasonably intelligible on its own, although the Committee emphasises that it should be read in the content of earlier reviews, especially the 1962 one.

It is clear that the Committee does not find the task of trying to estimate these genetic risks to man any easier with the passage of time and the accretion of data. One can sympathise with the members in their difficult task, for recent research on mammalian radiation genetics has tended to uncover additional complications rather than useful generalisations. The continuing lack of unequivocal evidence from man himself of genetic damage following irradiation is of course a good sign, but it means that assessments must be based very largely on results from the mouse. It is still uncertain to what extent these are likely to apply to mammals as a whole, especially to monotocous mammals like man.

Special attention is paid in the annex to the probable overall frequency of human chromosomal anomalies. There is also a comprehensive account of recent work on the induction of chromosomal and gene mutations in the mouse. This shows, for instance, the great importance of irradiation-tofertilisation interval in the female. Some results are also given of mutation studies in Drosophila, the silkworm etc., which mainly serve to demonstrate that certain phenomena described in the mouse are far from universal. 
Tentative risk estimates are made with respect to the acute irradiation of spermatogonia. However, the main value of this report is likely to be found in its detailed account of recent information on the genetic load in man and radiation mutagenesis in mammals.

A. G. Searle.

\section{BOOKS RECEIVED}

GEOGRAPHISCHE ANTHROPOLOGIE. Bertil Lundman. Gustav Fischer Verlag, Stuttgart. 1967. Pp. 228. DM 38, - 